\title{
Sobre espaço e experiência \\ Um olhar sobre a obra Untitled (1971) de Donald Judd na Glass House de Philip Johnson
}

\author{
Dely Soares Bentes*
}

Resumo o presente artigo se propõe a analisar a primeira obra site-specific de concreto do artista Donald Judd, Untitled (1971), construída no terreno da Glass House de Philip Johnson. Através do entendimento do trabalho de Judd dentro do contexto da minimal, somado às intenções compositivas de Johnson para o objeto implantado no núcleo histórico de sua icônica residência de vidro, pretende-se especular sobre os cruzamentos e sobreposições de ambos. As distintas percepções acerca do espaço e da experiência que impulsionam os autores, se complementam na criação do objeto que culmina na convivência autônoma e complementar dos tempos de Judd e Johnson.

Palavras-chave: Donald Judd, Glass House, Philip Johnson.

Sobre el espacio y la experiencia. Una mirada a la obra Sin título (1971) de Donald Judd en Philip Johnson Glass House

\begin{abstract}
Resumen El presente artículo se propone analizar la primera obra específica de concreto del artista Donald Judd, Untitled (1971), construida en el terreno de Glass House de Philip Johnson. A través del entendimiento del trabajo de Judd dentro del contexto de la minimal, sumado a las intenciones compositivas de Johnson para el objeto implantado en el núcleo histórico de su icónica residencia de vidrio, se pretende especular sobre los cruces y superposiciones de ambos. Las distintas percepciones acerca del espacio y de la experiencia que impulsan a los autores, se complementan en la creación del objeto que culmina en la convivencia autónoma y complementaria de los tiempos de Judd y Johnson.
\end{abstract}

Palabras clave: Donald Judd, Glass House, Philip Johnson.
On space and experience. A look at Donald Judd's Untitled (1971) at Philip Johnson's Glass House

Abstract The present article proposes to analyze the first site-specific work of concrete by Donald Judd, Untitled (1971), constructed in the site of Philip Johnson's Glass House. Through the understanding of Judd's work within the context of minimal art, coupled with Johnson's compositional intentions for the object implanted in the historic core of his iconic glass residence, it is intended to speculate on the crosses and overlaps of both. The different perceptions of space and experience that drive the authors, complement each other to create the object that culminates in the autonomous and complementary coexistence of Judd Johnson times.

Keywords: Donald Judd, Glass House, Philip Johnson. 

a ser um ícone arquitetônico do século XX. A singela edificação retangular de pouco mais de $150 \mathrm{~m}^{2}$ levou às últimas consequências a ideia da estrutura independente, evidenciando seu esqueleto metálico com fechamentos completamente transparentes. Em 1971, Donald Judd instalaria, nas imediações da casa de vidro, a sua primeira obra em concreto.

O trabalho de Judd foi encomendado por Johnson para ser implantado no terreno de 19 hectares localizado em New Canaan, em Connecticut. Lá, além da Casa de Vidro e da Casa de tijolos (figura 2) - conhecida como Guest House, idealizada como complementar à edificação transparente - o arquiteto construiu mais doze estruturas, algumas idealizadas para abrigar as obras que ele e seu companheiro, curador e crítico de arte, David Whitney colecionaram no longo de suas vidas em comum.

Pretendemos aqui analisar esta obra de Judd, não apenas a partir do contexto de sua própria produção e do momento histórico, cultural e artístico em que se insere, mas também especular sobre algumas possíveis leituras e conexões que poderiam existir entre os dois projetos - de Judd e de Johnson -, em especial a partir dos pontos de vista dos dois autores e de suas motivações e objetivos.

Por fim, nos propomos a problematizar uma ideia de que a obra de Judd estaria a serviço de uma estratégia compositiva montada por Philip Johnson para organizar os acessos e o entorno imediato da sua Glass House. Com esse objetivo, faremos uma contextualização da Minimal, seus antecedentes e suas chaves de leitura, focando na relevante contribuição de Donald Judd, que além das obras construídas, possui uma extensa produção teórica.

Analogamente, procederemos a uma breve análise do projeto da Casa de New Canaan em especial no que diz respeito às referências que Philip Johnson atribuiu a algumas de suas decisões e estratégias. Com esses subsídios, será possível então ponderar sobre as possíveis relações e leituras conjuntas dos objetos em questão, mais um exercício teórico em que propomos confrontar as intenções dos autores das duas obras em tela.

\section{Donald Judd e o Minimalismo}

Donald Judd iniciou a sua carreira como pintor e foi a partir de reflexões originadas nessa condição que ele escreveu o ensaio intitulado "Objetos específicos" (2006), em

* Dely Soares Bentes é Arquiteta e Economista, doutoranda do PROARQ-UFRJ e professora da PUC-RIO; ORCID <http://orcid. org/0000-0001-5016-8125>. 1965. O texto começa com a afirmação de que "a metade, ou mais, dos melhores novos trabalhos que se têm produzido nos últimos anos não tem sido nem pintura nem escultura" (JUDD, 2006, p.96). Ele se referia ali a pinturas cuja planaridade não se constituía mais em uma condição definidora da obra pictórica. 


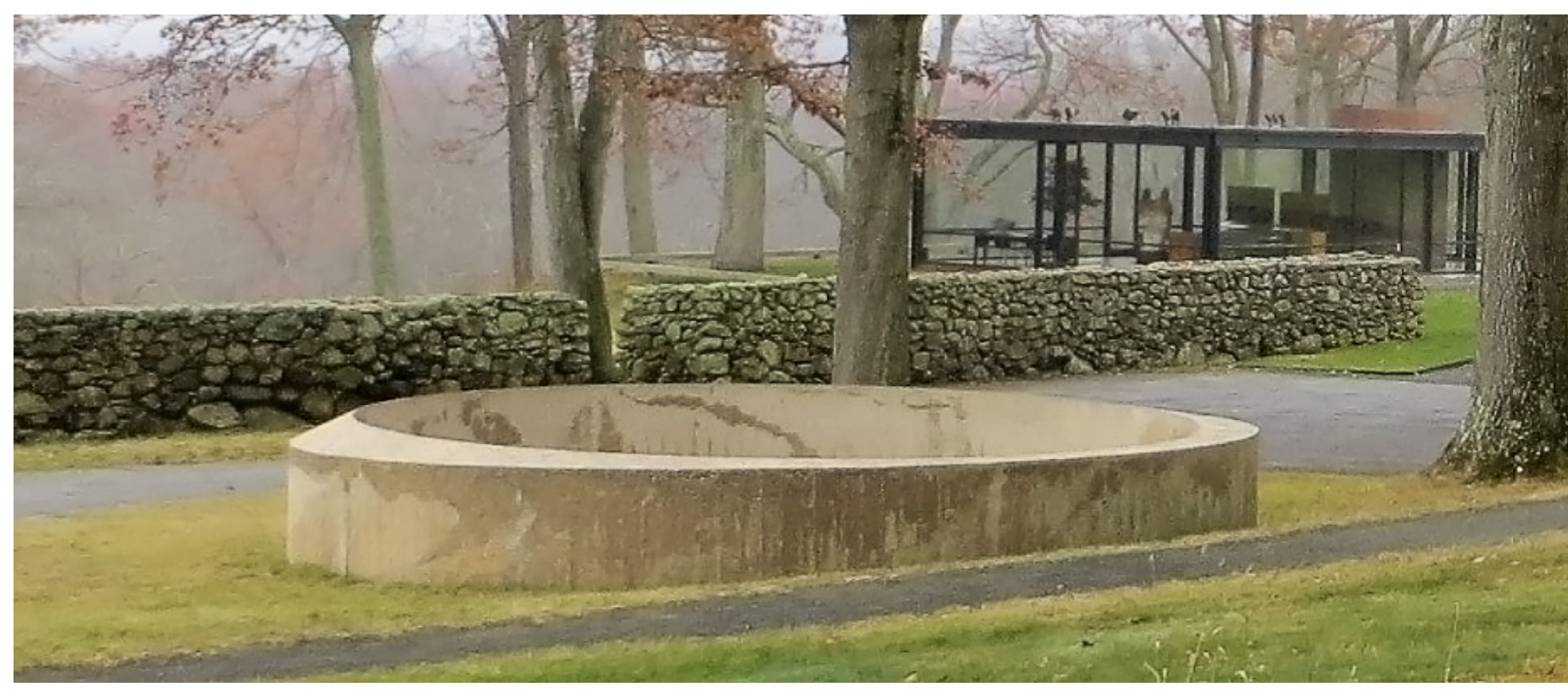

Figura 1: Untitled (1971) - Do-

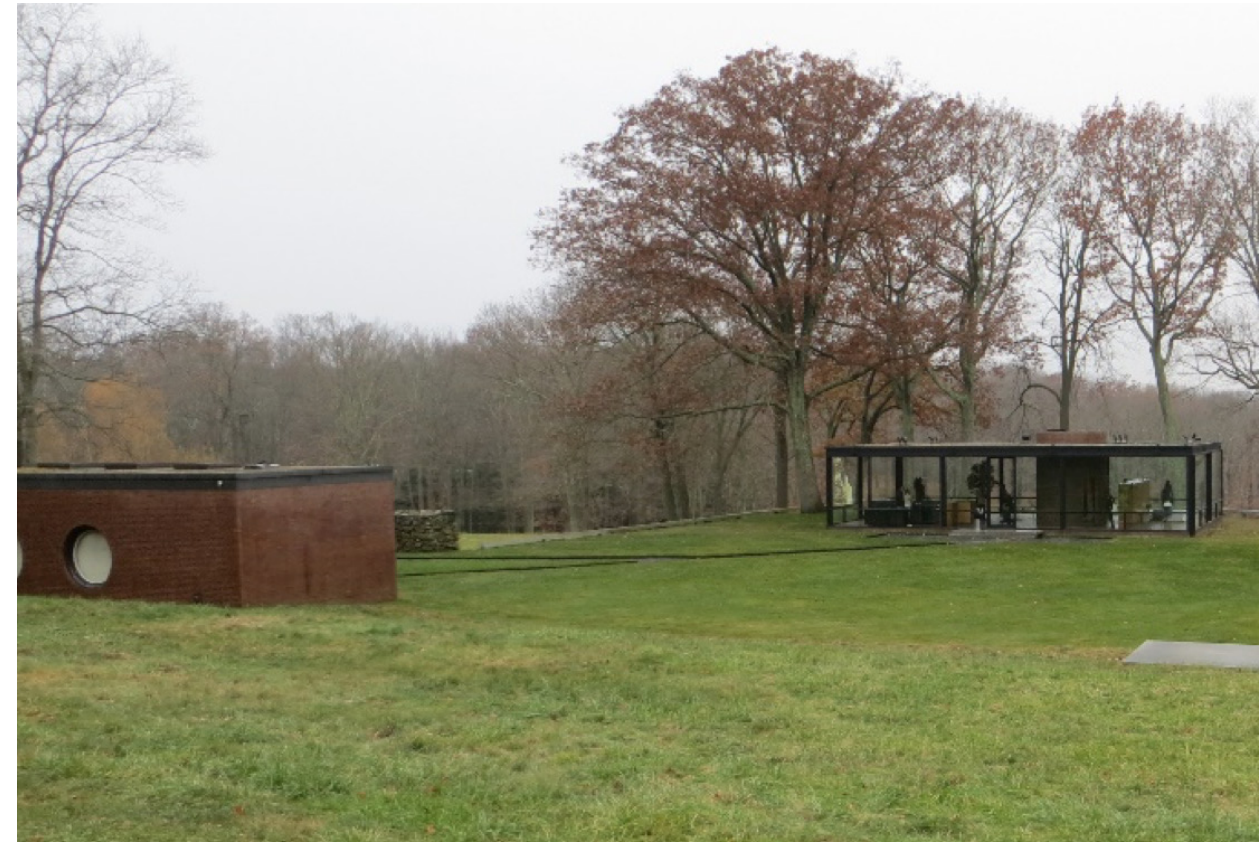
nald Judd. Fonte: Recorte sobre fotografia de José Barki, 2013.

Figura 2: Glass House à direita e Guest House à esquerda na imagem. Fonte: Fotografia José Barki, 2013. 
1 Barbara Rose é uma historiadora e crítica de arte norte americana que conviveu proximamente dessa geração de artistas, inclusive como esposa de Frank Stella entre 1961 e 1969.
Judd nomeou essas obras de objetos tridimensionais, uma vez que não se enquadravam nas definições ortodoxas de pintura e nem tampouco de escultura. São exemplares os trabalhos de Frank Stella, Robert Morris, Dann Flavin e do próprio Donald Judd, que a esta altura já estava produzindo as suas conhecidas sequências de formas regulares e caixas coloridas. No texto de 1965, ele não se preocupa em criar categorias para as obras e nem mesmo em buscar um lugar para que ocupassem na história da arte, como deixa claro na passagem que segue: "obviamente, o trabalho tridimensional não sucederá de maneira clara à pintura e à escultura. Não é como um movimento; de qualquer modo, movimentos já não funcionam mais; além disso, a história linear de algum modo se desfez". (JUDD, 2006, p.97)

O que se percebe na fala de Judd é a ideia do esvaziamento do conteúdo artístico, expressivo e emocional que havia dominado a geração imediatamente anterior, dos expressionistas abstratos. (ARCHER, 2008, p.43). Embora não fosse a sua vontade criar taxonomias para os objetos que identificara, os críticos de arte logo se preocuparam em classificar e também identificar a filiação dessas obras.

Michael Archer, em seu livro "Arte Contemporânea. Uma história concisa" (2006) faz referência à crítica Barbara Rose ${ }^{1}$ que foi a primeira pessoa a criar uma denominação para o conjunto de obras a que Judd se referia no seu ensaio "Objetos específicos". Ao escrever o artigo "ABC art", publicado também em 1965 na revista Art in America, Rose descreveu as características fundamentais da arte minimalista, bem como o que acreditava serem suas origens na história da arte. Segundo ela, os readymades de Duchamp e as pinturas de Malevich são o caldo de cultura onde se desenvolvera a Minimal. (ARCHER, 2008, p.43).

Todos esses questionamentos certamente não são originados apenas na esfera artística, mas são reflexos das profundas modificações que a sociedade sofreu a partir da II Guerra. Não por acaso essas manifestações começam a aflorar especialmente nos Estados Unidos, nação recém-elevada ao posto de grande potência. Além disso, distante o suficiente do peso da arte europeia, a ponto de conseguir romper com o percurso histórico de sua tradição. Os novos rumos do capitalismo e a instauração de uma sociedade de consumo em plena atividade impulsionaram questionamentos acerca do papel e da qualidade das obras de arte.

Donald Judd, no ensaio de 1965, afirmara que "um trabalho só precisa ser interessante". (JUDD, 2006, p.103). De acordo com o que pensava sobre o lugar que a produção artística deveria ocupar nessa sociedade em plena ebulição, ela não precisava ser complexa e nem envolver virtuosismo do artista; o material de que é feito não precisa ser nobre, uma vez que qualquer um, mesmo que produzido industrialmente, pode ser usado em seu aspecto natural ou até mesmo pintado (JUDD, 2006, p.103).

Em suma, o que a década de 1960 testemunhou foi uma grande abertura e uma ganho de liberdade e autonomia para as mais diversas expressões artísticas. As manifestações que sucederem a hegemonia do expressionismo abstrato - que havia surgido ainda na década de 1940, no imediato pós-guerra - tinham como característica principal a experimentação e a distensão dos limites. Assim, as pinturas "repletas de conteúdo emocional e expressivo" (ARCHER, 2008, p.43) cederam lugar a obras "vazias", em que o significado deixou de ser relevante, como enfatizado por Rosalind Krauss em seu livro "Caminhos da escultura moderna" publicado em 1977: 
A importância da arte surgida nos Estados Unidos no início dos anos 60 consiste em ter ela pautado tudo pela precisão de um modelo de significação apartado das pretensões de legitimidade de um eu particular. [...] os escultores minimalistas começaram com um procedimento para declarar a externalidade do significado. (KRAUSS, 1998, p. 318)

Para esses artistas, o significado da obra não está dado e não parte apenas do autor, mas se completa através da experiência, a partir das relações que estabelece com o lugar e com os espectadores. Assim, a luz, as relações com o contexto e as texturas fazem parte do conjunto de significados disponíveis e em abertura. A compreensão não está contida na peça em si, mas o conjunto de sensações e avaliações que podem ser despertadas individualmente.

Um dado relevante nesse contexto foi a edição de "Fenomenologia da percepção", de Maurice Merleau-Ponty (1999). Embora o livro tenha sido originalmente publicado na França em 1945, a tradução para o inglês só ocorreu em 1962. Os reflexos na arte e na arquitetura foram logo sentidos e a duração e a qualidade da experiência passaram a balizar o fazer artístico. Fabíola Zonno pontua essas questões em seu livro "Lugares Complexos. Poéticas da complexidade: entre arquitetura, arte e paisagem":

[...] o questionamento da forma autônoma pela Minimal, levou à tensão dos limites da escultura ao propor sua relação direta com o espaço real. Enfatiza-se a experiência espaço-temporal da obra como processo, a relação com o corpo e a participação do espectador. [...] A sensibilidade literal da Minimal enfatiza a relação de dependência entre o trabalho e a situação, que inclui o observador. Neste sentido, a arte evidencia a experiência perceptiva como fenômeno que se transforma continuamente. (ZONNO, 2014, p.34)

As obras minimalistas são simples, "uma coisa só" (JUDD apud ARCHER, 2008, p.56). Não é necessário e nem indicado perder tempo na compreensão da forma do objeto ou em busca de referências antropomórficas. A Gestalt clara poupa o esforço no entendimento da obra e pode transferi-lo para a apreciação de outros aspectos, como a textura, o material, o ambiente (ARCHER, 2008, p.57).

A direção natural desde a abertura desencadeada por essas experiências foi de que as fronteiras fossem ficando cada vez mais borradas e as obras cada vez mais de limite - entre pintura e escultura, entre escultura e arquitetura, entre paisagem e arquitetura. Os objetos tridimensionais a que Judd se referira foram ganhando cada vez maior autonomia e até mesmo extrapolando os espaços das galerias e museus.

Em 1979, Rosalind Krauss publica "A escultura no campo ampliado" (KRAUSS, 1984). Este texto viria a se configurar como fundamental para compreender a distensão e a sobreposição dos limites das obras de arte a partir da década de 1960. Nessa publicação seminal, a autora propõe a noção do campo ampliado para dar conta de tudo que vinha sendo categorizado como escultura. Assim, na tentativa de classificação, a autora lança a hipótese da dupla negação - não paisagem e não arquitetura - para definir a escultura. 
$2 \mathrm{Na}$ teoria dos grupos, o grupo de 4 de Klein é formado por quatro elementos, onde cada elemento é o inverso de si mesmo. Krauss explica o grupo da seguinte maneira: "(...) um conjunto de binários é transformado num campo quaternário que simultaneamente tanto espelha como abre a oposição original. " (KRAUSS, 1984, p. 134)

3 Cf. KWON, 2008.
À semelhança do Grupo Klein², Krauss constrói um diagrama, que através de negações e positividades, expande os domínios da escultura para além da definição até então reconhecida. Para tanto, a paisagem e a arquitetura são incorporadas ao campo e as combinações entre esses elementos e seus negativos resultam em uma nova categoria ou forma de intervenção artística. Deste modo, além da escultura - o que não é arquitetura e também não é paisagem - ela propõe mais três categorias no seu esforço em abarcar todos os tipos de manifestações até então de definição nebulosa.

\section{Untitled (1971)}

A obra de concreto de Donald Judd no entorno da Glass House é uma dessas que extrapolam os limites da escultura na medida em que está enraizada no local, foi construída e pensada para ocupar aquele espaço: é uma obra site-specific e como tal reage ao local em que está instalada. Miwon Kwon identifica o surgimento de trabalhos desse tipo a partir do final da década de 1960 e início da década de 1970. (KWON, 2008, p.167). Segundo sua definição, "O trabalho site-specific em sua primeira formação, então, focava no estabelecimento de uma relação inextricável, indivisível entre o trabalho e sua localização, e demandava a presença física do espectador para completar o trabalho" (KWON, 2008, p.167).

Kwon se aprofunda na classificação dos modelos site-specific e chega a classificá-los segundo três abordagens, a saber: o fenomenológico, o institucional e o oriented ${ }^{3}$. Não se trata, ela reforça, de uma classificação cronológica ou evolutiva, mas de meios de ação diferenciados e que não estão relacionados apenas ao local físico da intervenção. Desse modo uma única obra pode estar em consonância com mais de uma dessas posturas.A abertura do campo por si, como bem pontuado por Zonno, já seria capaz de promover essas associações mais fluidas. Em suas palavras:

Assim, pensamos ser possível afirmar para o campo ampliado tanto outras possibilidades de conexões entre disciplinas - pintura, teatro, literatura, fotografia, cinema, filosofia, etc. - como a complexificação do próprio conceito de paisagem, que não se restringe à dimensão física, material, é entrelaçado a um campo da cultura mais amplo, a questões sociais, políticas, históricas etc. - constituindo um campo tanto fenomênico como discursivo. (ZONNO, 2008, p.39)

Segundo James Lawrence, crítico e historiador de arte, a obra que Judd constrói nas imediações da Glass House de Philip Johnson em New Canaan, é seu primeiro trabalho em concreto. (LAWRENCE, 2010). Faz parte de uma série de objetos topográficos, tal como os denominam Lawrence, que começaram a ser experimentados algum tempo antes, no próprio ano de 1971. A primeira especulação dessa natureza que Judd produziu foi uma peça quadrada em aço, efetivamente composta de dois planos, sendo o interno nivelado com o terreno e o externo perfeitamente horizontal (figura 3). Depois dessa, mais duas peças, ambas em aço, conjecturam com a dualidade entre o ideal e o real e experiências espaciais melhor descritas por James Lawrence:

O equilíbrio das condições gerais e específicas reside na conversão do terreno local em um único plano inclinado, o que contrasta com a horizontal ideal que reforça nosso senso psicológico de equilíbrio. Os trabalhos topográficos de Judd reconciliam três ordens de experiência espacial: a condição global de horizontalidade, as condi- 
Figura 3: Untitled, 1971. Aço inox. Coleção Pulitzer, St. Louis, Missouri. Fonte: <https://chinati. org/pdf/newsletter15.pdf>.

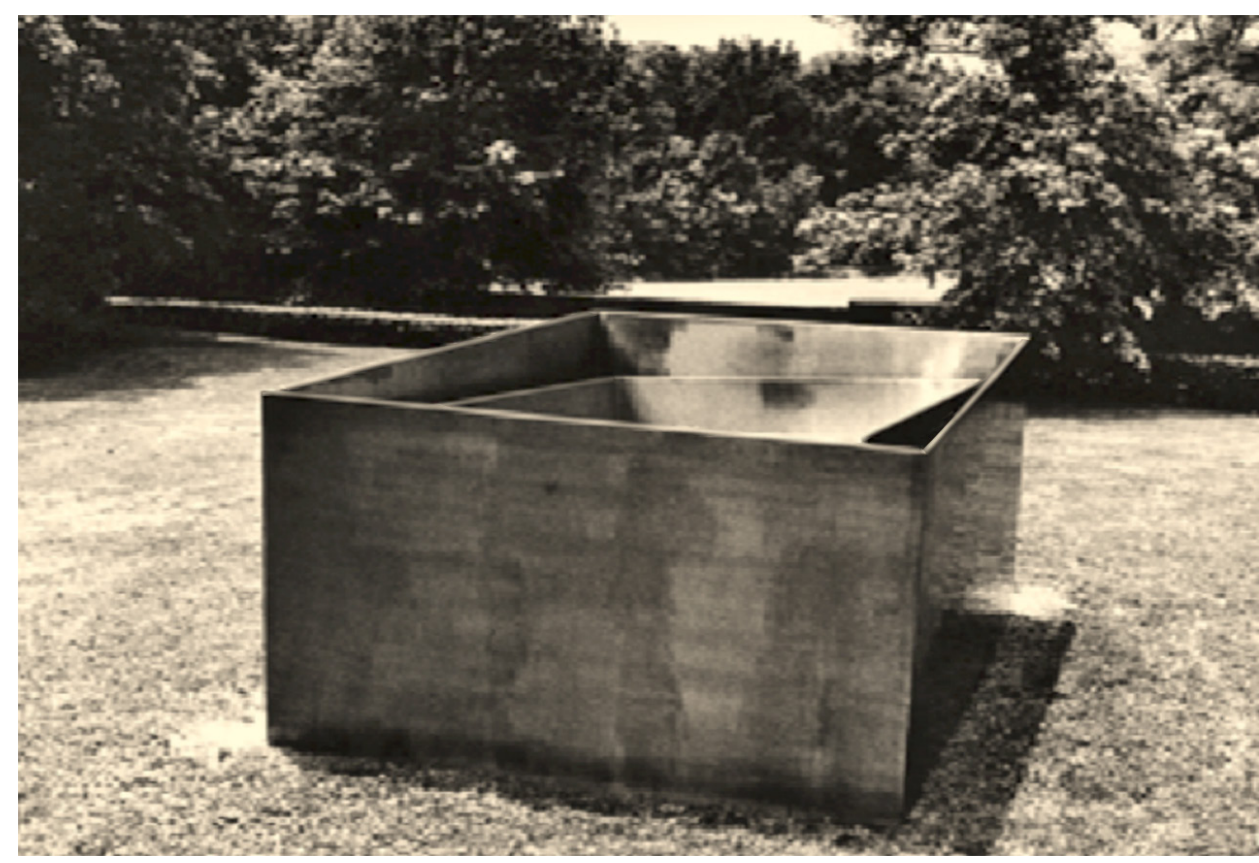

ções locais da paisagem e um traço fisiológico que é simultaneamente central para a experiência individual e comum em toda espécie humana. (LAWRENCE, 2010, p. 7, tradução nossa)

Para completar a percepção da obra, é necessário percorrê-la, circundá-la, e então sentir e experimentar o que ocorre ao seu redor, como reage ao local e em relação ao espectador. Assim, cada percepção é única e individual. Não se trata de um objeto retiniano, mas de uma obra que envolve o corpo, o lugar e a experiência. Esse objeto não apenas abriu mão de um suporte, de um pedestal, como se relaciona inexoravelmente com o lugar onde foi posicionado. Não há possibilidade de ser remanejado sem perder o seu sentido.

Donald Judd comentou a respeito das obras "topográficas" e de Untitled(1971) em especial em um texto de 1993. Neste escrito é a questão do espaço, ou melhor, da criação do espaço o tema central. Ele inicia a explanação com a seguinte afirmativa: "Qualquer obra de arte, antiga ou nova, é prejudicada ou favorecida pelo local onde é colocada" (JUDD, 2016, p.811, tradução nossa). Antes de tudo, isso denota a sua crença na inexistência de um espaço neutro. Para ele o espaço é resultado de uma operação, ele é construído.

O artista identifica no conjunto de obras que produz ao longo da década de 1970, que de certa maneira problematizam o lugar e a paisagem, a possibilidade de criação de espaço. Segundo afirma, algo inédito para as artes: "A menor e mais simples obra cria espaço ao redor dela, desde que há muito espaço em seu interior. Isto é novo na arte, não na arquitetura evidentemente. " (JUDD, 2016, p.811, tradução nossa). E quando ele se refere à obra da Glass House, no mesmo ensaio da década de 1990, fala sobre um "sólido que encerra um grande espaço" (JUDD, 2016, p.815). 
Figura 4 (esq): Untitled (1971). Aço. Museu Guggenheim, Nova Iorque. Destruído. Fonte: <https://chinati.org/pdf/newsletter15.pdf>.

Figura 5 (dir): Detalhe de Untitled (1971). Fonte: Recorte sobre fotografia de José Barki, 2013.
Em outras palavras, poderia ser dito que os negativos fazem parte da obra, tanto quanto os positivos. A acumulação de matéria que o concreto evidencia, igualmente define um interior e um exterior, onde o que não é a obra, ainda assim faz parte de sua leitura. A ideia da apropriação dos negativos, de algo que é construído pela adição de matéria e não pela remoção dela, foi um dos princípios do minimalismo. Rosalind Krauss disserta sobre o assunto usando como referência uma obra que Judd desenvolveu para a galeria Leo Castelli em 1970, "Untitled". Em suas palavras:

A própria interpretação visual das duas progressões - uma de volumes, a outra de vazios - converte-se em uma metáfora da dependência da escultura com relação às condições do espaço externo, pois é impossivel determinar se é o volume positivo do trabalho que gera os intervalos ou se é o ritmo dos intervalos que estabelece os contornos do trabalho. (KRAUSS, 1998, p.324)

Quando as obras começam a ganhar proporções maiores, em especial as que são produzidas para ocupar locais descobertos, então a questão da geração do espaço também assume dimensões (físicas) mais arquitetônicas, como pontuado pela fala de Judd, acima. Consequentemente, se amplifica a relação dos objetos com o corpo e com o entorno.

Diante disso, o maciço circular de grandes dimensões moldado em concreto que Judd constrói nas imediações da Casa de vidro de Philip Johnson, sintetiza algumas posturas próprias das obras site-specific. A escolha do material possibilita a criação de um volume único, o que deixa mais evidente o acúmulo de matéria, pois no lugar de dois planos independentes curvados em aço (figura 4) - como em uma das experimentações topográficas que o artista havia ensaiado anteriormente para uma exposição temporária no Museu Guggenheim de Nova lorque -, um espesso plano curvado de quarenta e cinco centímetros evidencia as diferenças de altura dos círculos (figura 5).
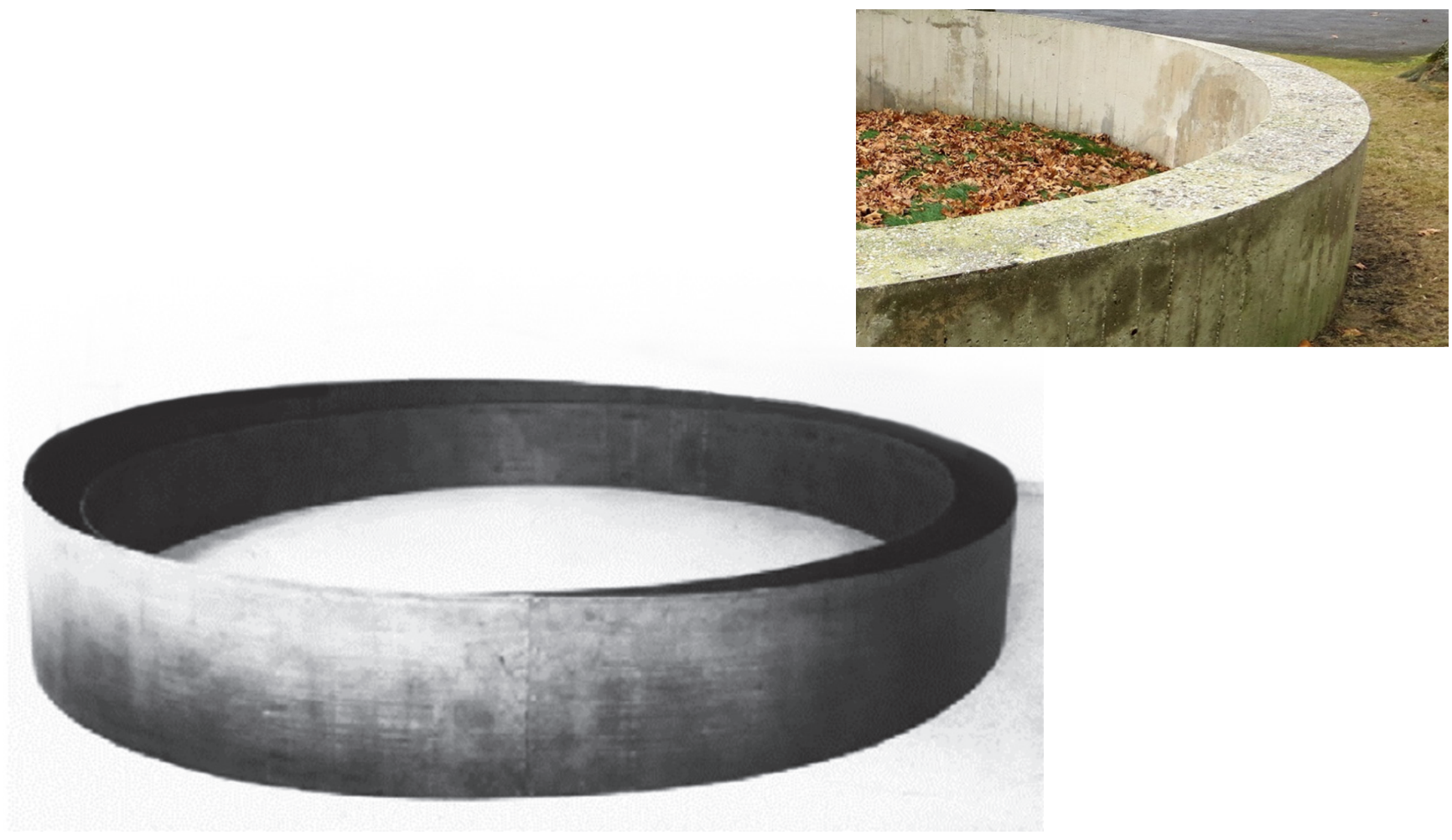
4 Observação da crítica de arte Margarida Brito Alves ao dissertar sobre uma obra de Donald Judd em uma palestra no Museu Coleção Berardo em Lisboa. Disponível em <http://www.youtube. $\mathrm{com} /$ watch?v=tE7kRY2cbJA>.

Figura 6a: Desenho de execução da obra Untitled (1971) - Planta Baixa. Fonte: <http://3hcgph4f 4ng73726ly295p9f.wpengine. netdna-cdn.com/wp-content/ uploads/2014/12/JUDD.SITE_. PLAN_.DOWNLOAD.pdf>.
O material escolhido também permite revelar registros da construção. São visíveis as marcas deixadas pelas formas estreitas que foram utilizadas para despejar o concreto ainda liquefeito (figura 5). Contudo, apesar de a peça preservar os traços desse processo, ela não exibe nenhum vestígio do artista. A participação do autor está restrita ao projeto da obra. Judd e outros artistas da Minimal se esforçaram em reiterar o que Rosalind Krauss chamara de "ausência do artista" (KRAUSS, 1998, p. 52).

Com esse intuito, a execução dos objetos era delegada a outros profissionais, que seguiam instruções detalhadas do autor. Na figura 6 é possível ver os desenhos de execução da peça. Facilmente poderiam ser confundidos com um detalhamento arquitetônico qualquer; o mesmo se pode falar sobre o material. Não há no concreto nenhuma nobreza que transfira valor à obra e nem tampouco que o diferencie de qualquer outra construção comum.

Além disso, o objeto ocupa o mesmo plano contaminado que nós ocupamos ${ }^{4}$, não está em um espaço solene, nem sobre uma base, mas emerge do mesmo solo que os seus espectadores, ou talvez melhor assim, daqueles que o experienciam. A obra, também por suas dimensões - o círculo exterior mede 3,80 metros de diâmetro e o interior 3,35 -, se relaciona de forma muito física com as pessoas. A altura, que varia entre 90 e 120 centímetros, instiga a curiosidade e convida instintivamente à aproximação. Como Miwon Kwon constatara sobre os trabalhos site-specific, Untitled é também um objeto criado para ser "experimentado singularmente no aqui-e-agora pela presença corporal de cada espectador" (KWON, 2008, p.167).

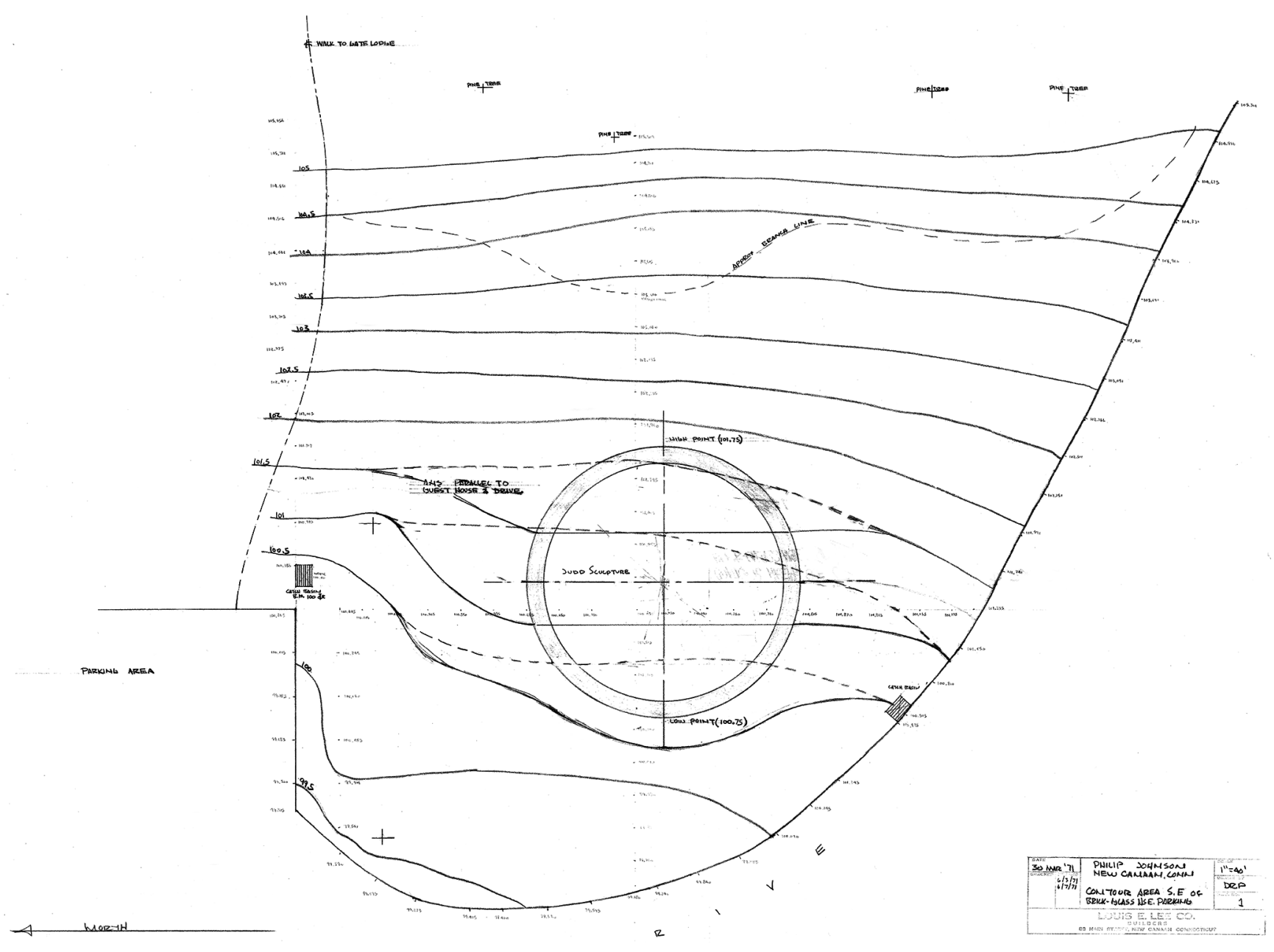


Figura 6b: Desenho de execução da obra Untitled (1971) - Corte. Fonte: <http://3hcgph4 f4ng73726ly295p9f.wpengine. netdna-cdn.com/wp-content/ uploads/2014/12/JUDD.PLAN_. SECTION.DOWNLOAD.pdf>.

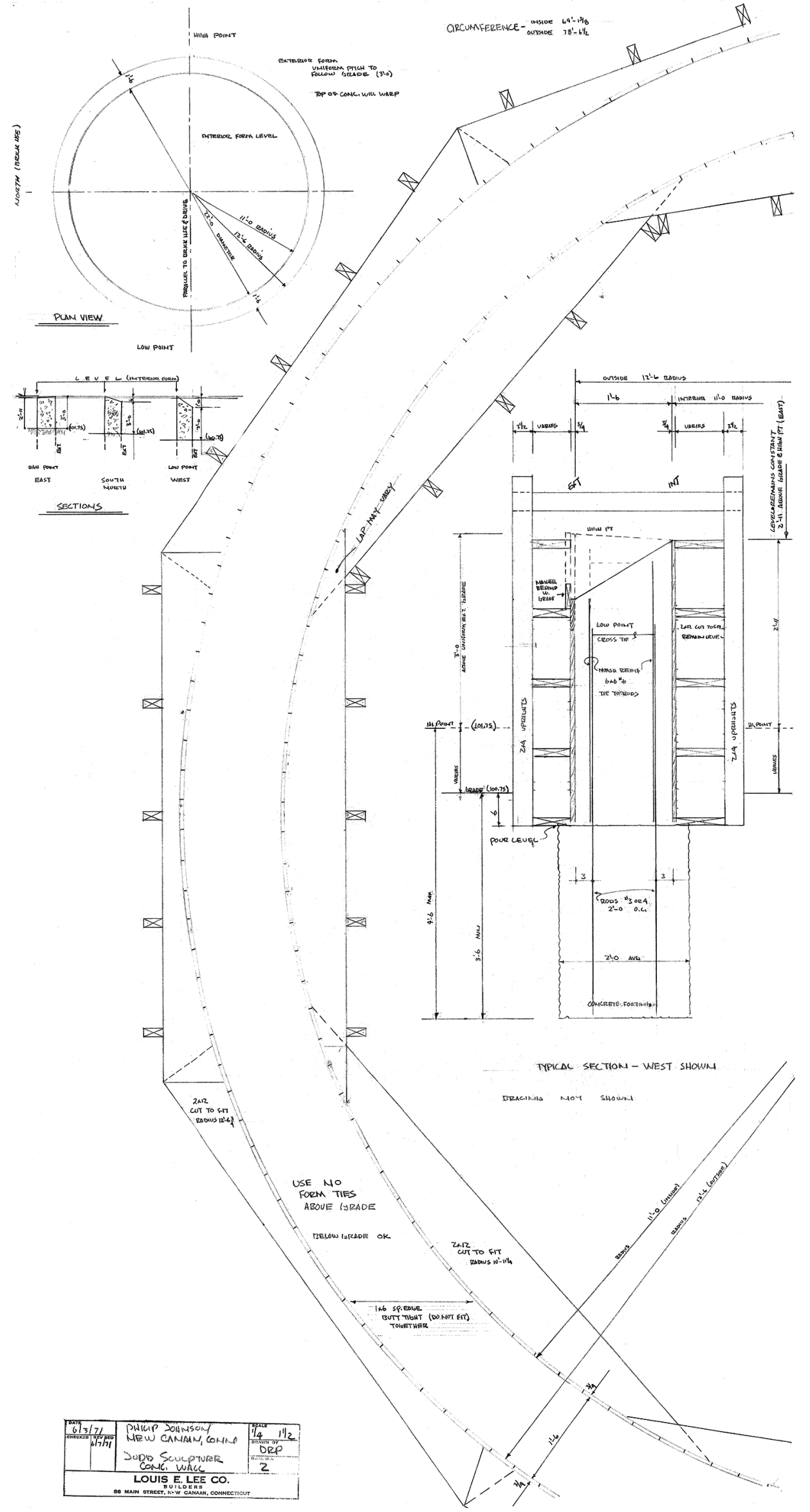




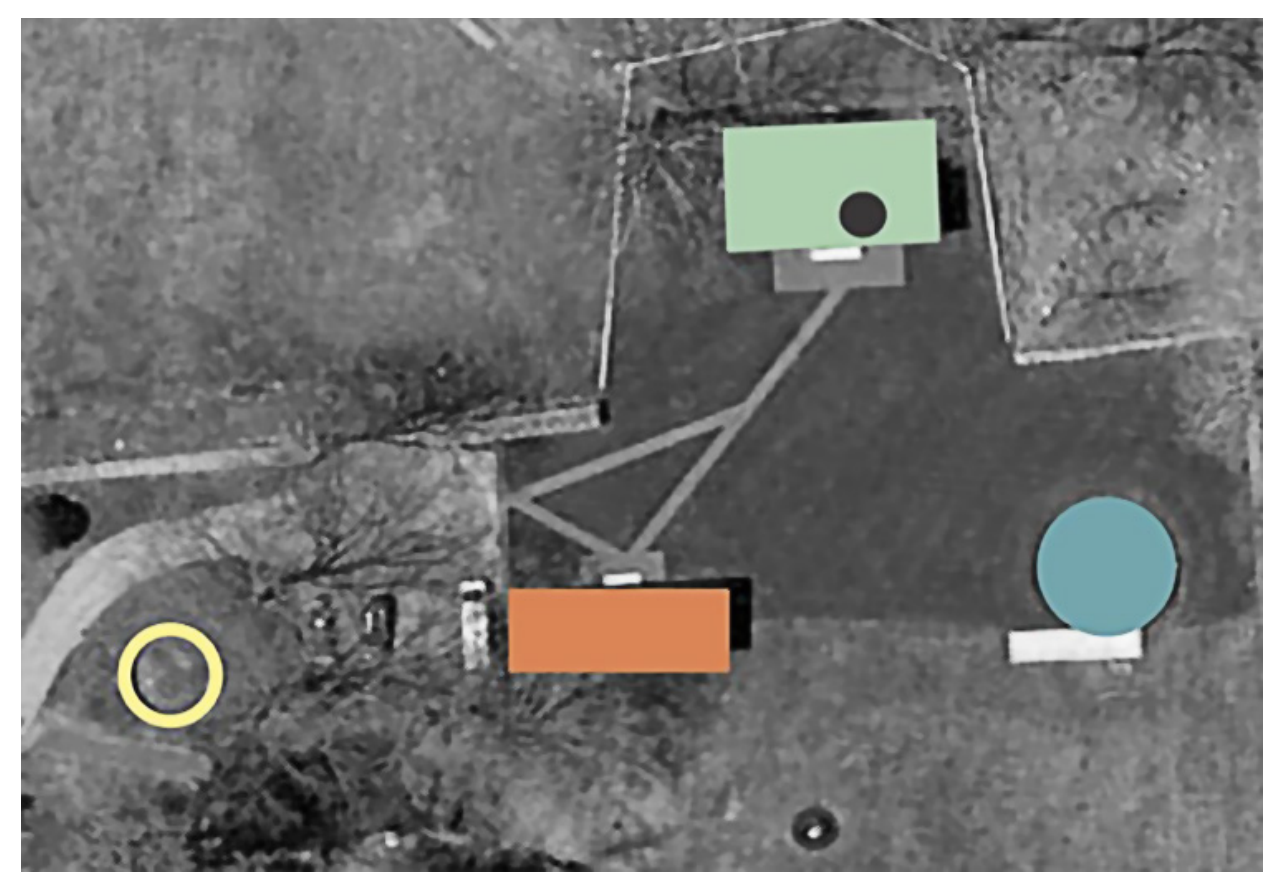

Figura 7: Implantação do núcleo histórico da Glass House. Fonte: Marcações da autora sobre imagem disponível em <googlemaps>.

5 A construção da casa de Mies foi concluída apenas em 1951 e a de Johnson em 1949, no entanto o projeto da Farnsworth data de 1947 e fez parte da exposição acerca da obra de Mies - que ocorreu no MoMA no mesmo ano da conclusão do projeto - cuja curadoria coube a Philip Johnson. A Glass House é um resultado de conversas entre os dois arquitetos e especulações sobre a possibilidade de se construir uma casa totalmente envidraçada. (Cf. JOHNSON, 1991).

6 A revista "G" foi editada entre 1923 e 1926 por Mies van der Rohe e Theo van Doesburg, com diagramação e tipografia de El Lissitzky.

\section{A Glass House}

Além da análise da obra de Judd isoladamente, pretendemos lançar algumas especulações acerca das possíveis relações com a Glass House e seu contexto imediato. Para tanto, é necessário retroceder e compreender as motivações e justificativas de Philip Johnson para a sua casa de vidro. O projeto de Johnson em New Canaan - sua residência desde a construção, em 1949, até sua morte em 2005- foi concebido pelo arquiteto a partir de um conjunto de referências elencadas em um texto autoral publicado originalmente na revista Architectural Review de setembro de 1950 (JOHNSON, 1993).

Além da menção óbvia à Casa Farnsworth e ao conjunto da obra de Mies van der Rohe $^{5}$, Johnson aponta diferentes inspirações, que vão desde a Acrópole grega até Le Corbusier, passando por Schinkel e Ledoux. (JOHNSON, 1993, p.11). Contudo, no contexto das reflexões que pretendemos desenvolver aqui, não nos cumpre empreender uma análise mais elaborada do projeto de Philip Johnson, mas algumas observações do arquiteto são relevantes para as considerações que propomos construir acerca das possíveis relações com a obra de Donald Judd.

O posicionamento da Glass House (em verde da figura 7) e da Guest House (em laranja na figura 7), as quais Johnson trata como complementares, seguem uma lógica que o arquiteto atribui ao movimento De Stijl. Sua referência confessa é, contudo, um artigo de Theo van Doesburg intitulado "The Basso Continuo of Painting", publicado em 1922 na revista "G"6; o texto é ilustrado por um desenho 


\begin{abstract}
7 Philip Johnson foi curador, junto com Henry-Russel Hitchcock, da Exposição Internacional de Arquitetura Moderna, que aconteceu no MoMA de Nova lorque em 1932. Essa exposição, bem como o livro que escreveram no mesmo ano, "The International Style: Architecture since 1922", ajudaram a associar a obra de Mies com o recém-cunhado "estilo internacional".
\end{abstract}

Figura 8: Theo van Doesburg. Fonte: JOHNSON, 1993, p.10. do artista (figura 8) onde aparecem retângulos assimétricos que parecem deslizar uns em relação aos outros.

Princípio similar Philip Johnson afirma ter seguido a partir do que descreve como a "teoria de Mies de organizar edifícios em grupo" (JOHNSON, 1993, p.10), na qual, em uma estratégia semelhante a de van Doesburg, os edifícios, ainda que seguindo uma orientação retilínea, apresentam deslizamentos e sobreposições segundo uma lógica assimétrica (JOHNSON, 1993, p.10). Johnson afirma ter se inspirado nessas referências ao propor a posição dos edifícios da propriedade de Connecticut.

Outra influência que o arquiteto aponta é uma obra do pintor suprematista Kazimir Malevich de 1913, "Circle" (figura 9). Mais que a obra em si, Johnson se refere às possibilidades que o artista mostrou haver no posicionamento de um círculo dentro de um retângulo (JOHNSON, 1993, p.12); e também, todas as discussões que podem ser derivadas dessa observação, como as relações de figura e fundo e os espaços "negativos" que são apropriados ao conjunto. São dessas reflexões que o arquiteto afirma ter partido ao propor a solução da planta da sua casa de vidro: um círculo (o volume de tijolos que abriga o banheiro e a lareira) posicionado no interior de um retângulo (figura 10).

Essas referências não causam espanto se entendidas no contexto em que o projeto foi construído. Johnson é um verdadeiro herdeiro do movimento moderno, discípulo e admirador de Mies van der Rohe7, mas no pós-guerra já flerta com o pós-modernismo, movimento com o qual viria a ser identificado posteriormente.

Como o próprio autor evidencia, existem referências a arquiteturas do passado em seu projeto, as quais ele não se furta em revelar. A mistura de materiais que ele utiliza
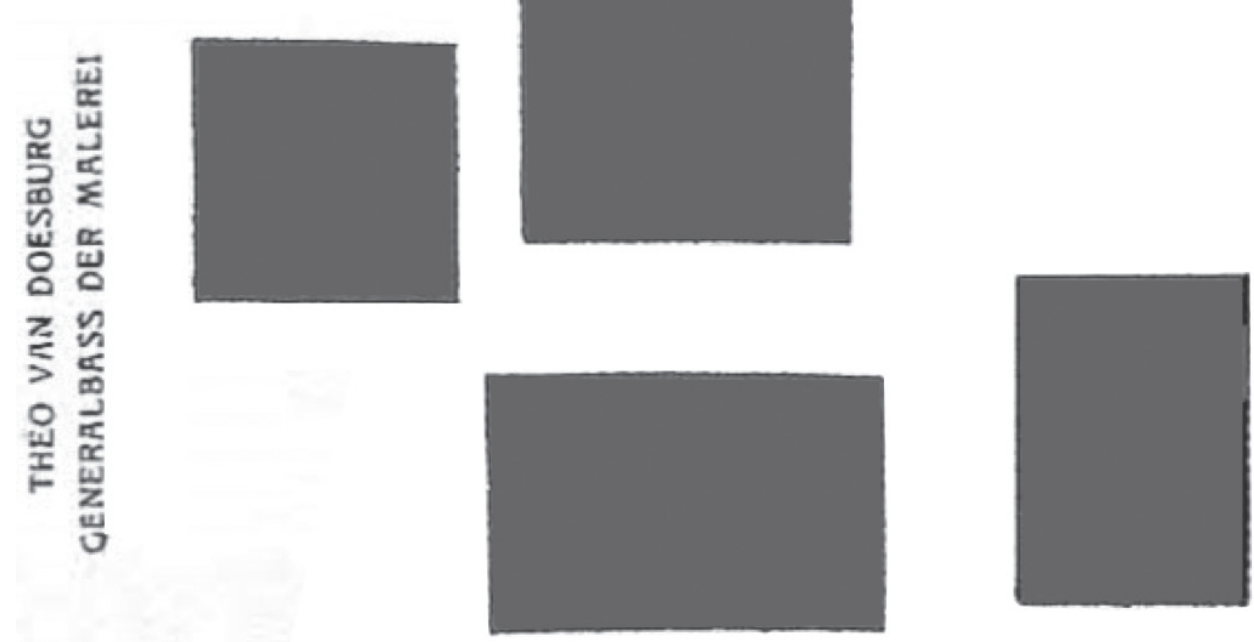

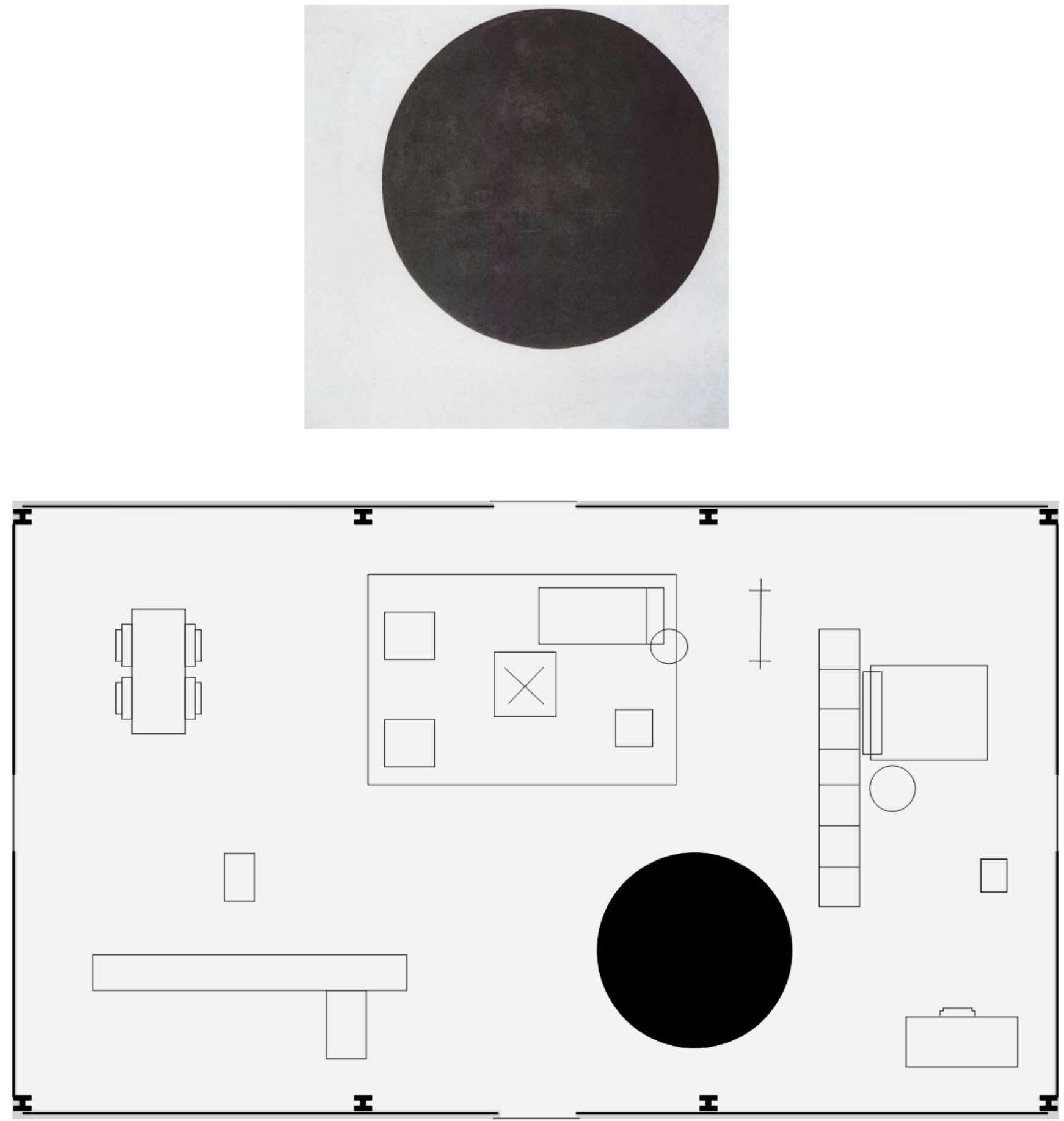

Figura 9 (em cima): Circle(1923) K. Malevich. Fonte: <https://uploads4.wikiart.org/images/kazimir-malevich/black-circle-1923.jpg>.

Figura 10 (embaixo): Planta baixa da Glass House com círculo destacado em preto sobre o volume do banheiro e da lareira. Fonte: Redesenho da autora. 
8 Kenneth Frampton, em artigo reproduzido no livro de 1993 , "Philip Johnson: the Glass Hou$s e^{\prime \prime}$, analisa algumas das versões anteriores. (FRAMPTON, 1993, p. 93)
9 Na análise de Kenneth Frampton, existe um desenho que mostra um formato retangular e mais próximo às casas para a piscina. Mesmo para a implantação desse elemento houve especulações da parte de Johnson. (FRAMPTON, 1993: 106) igualmente denota um olhar também focado nas tradições vernaculares. O tijolo cerâmico, que se repete no piso e no volume cilíndrico na casa principal, reina soberano como revestimento da casa de hóspedes.

Johnson relata ter passado vários anos especulando sobre o projeto das casas até chegar ao formato final ${ }^{8}$. Assim, as preocupações que demostrou com a ocupação do terreno, a escolha do local exato em que implantou esse núcleo central, certamente nos fazem supor que a mesma precisão cirúrgica tenha acompanhado a construção de cada um dos elementos que ali instalou.

Apesar de Philip Johnson e Donald Judd serem amigos, parece improvável que a definição da obra tenha partido de Johnson, porém, soa razoável que ele tenha indicado o local da implantação para Judd, tendo em vista o desvelo que demostrava ter com o posicionamento de qualquer estrutura no terreno de Connecticut. No entanto, isso não significa necessariamente que o artista tenha trabalhado com as mesmas motivações que eventualmente impulsionaram o arquiteto.

\section{Possíveis leituras: Judd e Johnson}

Embora não haja dados concretos sobre a possibilidade de que a obra tenha sido discutida por Judd e Johnson, existe, no sítio eletrônico da Glass House, a seguinte descrição sobre a mesma:

A primeira obra de concreto de Donald Judd, Untitled, 1971, foi o último elemento inserido no núcleo histórico da propriedade. A escultura completa a composição de "retângulos assimétricos deslizantes" e de "círculos" que Johnson descreveu no primeiro artigo publicado sobre a Glass House, "House at New Canaan, Connecticut," Architectural Review, Setembro de 1950. Localizada no final do acesso e contornando a esquina, a escultura de Judd direciona os visitantes ao redor dela e em direção à entrada da Glass House, integrando o percurso coreografado idealizado por Johnson. (THE GLASS HOUSE. grifo nosso, tradução nossa)

A primeira parte dessa afirmativa está relacionada diretamente com as referências que enumeramos anteriormente: Mies van der Rohe, Theo van Doesburg e Kazimir Malevich. Os retângulos são as casas e os círculos seriam, não apenas o cilindro de tijolos cerâmicos que rompe o paralelepípedo de vidro da casa, mas também a piscina ${ }^{9}$ (em azul na figura 10), incorporada ao conjunto no ano de 1955. Pela descrição acima, Untitled seria o terceiro círculo (em amarelo na figura 10) a participar da composição idealizada por Johnson.

No entanto, a ideia de fazer parte de uma composição parece absolutamente contrária aos princípios de Donald Judd, para quem qualquer ideia de arranjo formal deveria ser rechaçada. Krauss, citando Judd e Frank Stella, enfatiza o quanto para aqueles artistas era importante não estabelecer relações. Utilizando o mote de "uma coisa após a outra", eles buscavam se afastar da ideia da composição relacional, que julgavam estar associada à arte europeia, da qual almejavam se libertar (KRAUSS, 1998, p. 292).

Portanto, ainda que a intenção de Johnson fosse a de incluir ali um elemento que completasse a estrutura compositiva que possivelmente imaginara para o en- 
10 Auguste Choisy escreveu o livro "Histoire d'Architecture" publicado originalmente em 1899 (COLQUHOUN, 2004, p.131). Neste texto, o autor procede a uma descrição detalhada sobre a implantação dos edifícios e monumentos no núcleo da acrópole ateniense. Em sua opinião, as dimensões e posições dos elementos são milimetricamente estudadas, de tal forma que os pontos de vista do observador sejam controlados de forma a se obter o efeito visual desejado.

11 A promenade architecturale proposta por Le Corbusier parte do princípio que a obra arquitetônica deve ser apreciada em movimento, e não a partir de um ponto fixo de onde se perceberia todo o edifício, e onde, portanto, a ideia de simetria clássica é valorizada.

Figura 11: Aproximação à obra Untitled (1971) através do caminho que conduz à Glass House. Fonte: Fotografia José Barki, 2013. torno imediato de suas casas de vidro e de tijolos, não se pode atribuir a Judd o mesmo propósito. A obra que propõe ali, mais parece a continuação de uma experiência que já vinha testando em outros trabalhos anteriores, como mencionado por James Lawrence em relação às obras topográficas de Donald Judd (LAWRENCE, 2010).

Com relação ao percurso, é fato que Johnson projetou o acesso à casa de vidro de tal maneira que a aproximação fosse lateral, tal como a descrição de Choisy ${ }^{10}$ sobre a acrópole de Atenas (JOHNSON, 1993, p. 10). Além disso, há a alusão à promenade architecturale, ${ }^{11}$ de Le Corbusier, em que se incorpora o movimento e o tempo à fruição arquitetônica. Johnson programou o percurso à casa de tal forma que o primeiro ponto de que é possível avistá-la fica justamente na curva que também comporta o trabalho de Judd.

Assim, como o acesso à Glass House passa necessariamente pela obra de Judd, parece que o artista também se apropria dessa possibilidade, de ter a obra posicionada em um ponto estratégico da curva de acesso ao conjunto, para demostrar ao observador que é necessário percorrê-la por completo, em mais de um ponto de vista para que se apreenda toda a sua complexidade aparentemente disfarçada numa forma simples e num material comum. Na figura 11 é possível ver três instantâneos do percurso do observador em direção à obra. A depender do ponto de vista, é possível percebê-la de uma maneira diferente. São motivações distintas - as de Johnson e Judd - mas nesse caso parecem atender a propósitos semelhantes.

Untitled é um objeto site-specific, pois responde às questões físicas do local, que fica marcado nas diferenças de níveis dos círculos interior e exterior. Mas ela também é site-specific, pois se afeta pela local que se encontra e não deixa despercebida a proximidade com a Glass House. Miwon Kwon, ao dissertar sobre esse tipo de obra observou que o site não se limita à estrutura física, mas se estende às contingências culturais do local onde é instalada (KWON, 2008, p.168), e a obra de Judd não parece escapar a essa definição.

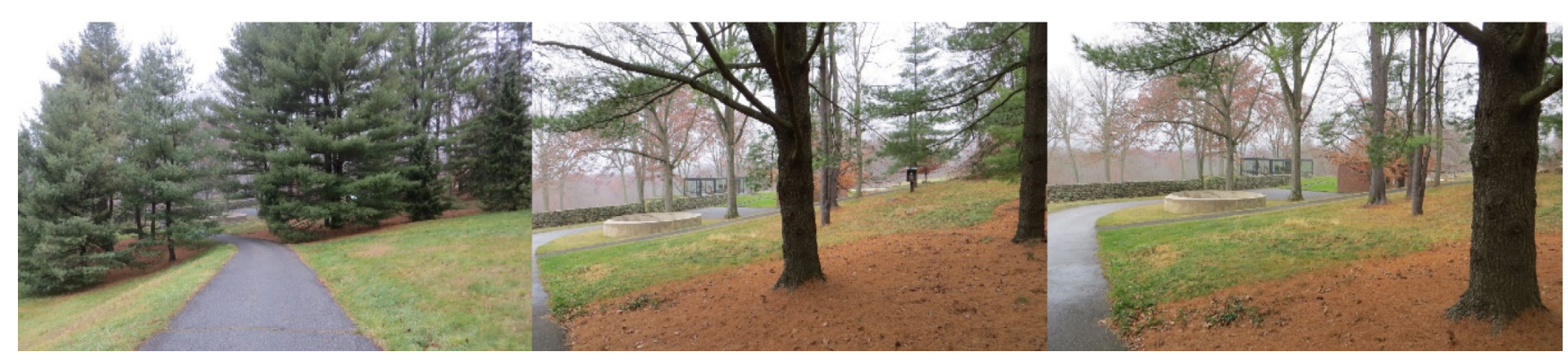


Nesse sentido, a opção pelo uso do concreto, parece também se relacionar dialeticamente com a leveza e a transparência do projeto de Philip Johnson. A acumulação de matéria que esse material demonstra, inaugura também um novo tipo de experimentação de Judd, com peças maiores e que evidenciam mais a criação do espaço. James Lawrence faz uma observação sobre a obra de aço instalada na rampa de acesso do Museu Guggenheim de Nova lorque (figura 4) que pode ser útil para compreender a possível associação da obra Untitled com a Glass House.

Os círculos de aço concêntricos que constituem a peça também ecoaram o padrão circular no piso, enquanto o arranjo concêntrico sintetizou a estrutura helicoidal do interior de Frank Lloyd Wright. Os objetos topográficos, com seus arranjos concêntricos, espaços fechados e raízes firmes em um determinado local, sugerem prontamente uma abordagem espacial que pertence tanto à arquitetura e ao ambiente planejado, quanto à escultura e as belas-Artes. (LAWRENCE, 2010, p.7, tradução nossa)

Essa colocação de Lawrence nos leva a ponderar sobre uma atitude análoga em relação à Glass House. Nesse sentido, interpretar o projeto de Johnson, suas formas, materialidade, não significa necessariamente se submeter às possíveis intenções compositivas do arquiteto, mas reagir ao sítio em toda sua amplitude, como observado por Kwon (KWON, 2008, p.168). A fase que Judd inaugura com os projetos topográfios e os de concreto caminham para uma amplitude espacial que conduz os trabalhos ao limite da condição arquitetônica.

Não por acaso, no mesmo ano de 1971, Donald Judd viria a adquirir um terreno em Marfa, no Texas, para onde se mudaria e, à semelhança de Johnson em New Canaan, passaria o resto da vida construíndo estruturas e adquirindo e produzindo obras para transformar o local em uma grande galeria a céu aberto. O que parece, enfim, é que Judd e Johnson são igualmente instigados pela criação e a manipulação espacial, porém as estratégias para fazê-lo é que diferem.

Tanto a Glass House de Johnson quanto Untitled de Judd são sobre espaço. Sobre cheios e vazios, sobre dentro e fora, sobre estabilidade e instabilidade. Enquanto o círculo de concreto evidencia a instabilidade do terreno, as casas de vidro e de tijolos de Johnson se impõem soberanas desafiando a topografia. Enquanto a grossa camada de material mineral de Judd define inexoravelmente o interior e o exterior, o fechamento diáfano de Johnson confunde esses limites.

A obra de Judd afeta e se deixa afetar pelo sítio, pelo mundo e pela sociedade que a contextualiza. Um mundo em que as certezas cederam lugar às incertezas, em que a crença num futuro estável e melhor foi substituída pela consciência da imprevisibilidade e da fragilidade das condições. E é nesse terreno movediço e escorregadio que Untitled busca se inserir. E então ela se acomoda ao lugar - fisica e figurativamente - mas também o questiona deixando o rastro de seu tempo, de sua matéria. Assim, como uma camada que se sobrepõe a outra mas sem apagá-la convivem os tempos de Jonhson e Judd. 


\section{Referências bibliograficas}

\section{Livros}

ARCHER, Michael. Arte contemporânea: uma história concisa. São Paulo: Martins Fontes, 2008.

COLQUHOUN, Alan. Modernidade e tradição clássica: ensaios sobre arquitetura 1980-87. São Paulo: Cosac \& Naify, 2004.

JUDD, Flavin; MURRAY, Caitlin. Donald Judd Writings. New York: Judd Foundation; David Zwirner Books, 2016.

KRAUSS, Rosalind. Caminhos da escultura moderna [1977]. São Paulo: Martins Fontes, 1998.

MERLEAU-PONTY, Maurice. Fenomenologia da percepção [1945]. São Paulo: Martins Fontes, 1999.

ZONNO, Fabíola do Valle. Lugares Complexos, poéticas da complexidade: entre arquitetura, arte e paisagem. Rio de Janeiro: Editora FGV, 2014.

\section{Artigos}

FRAMPTON, Kenneth, The Glass House Revisited [1978] in: WHITNEY, David, KIPNIS, Jeffrey. Philip Johnson: the Glass House. New York: Pantheon Books, 1993, p. 92-113.

JOHNSON, Philip. House at New Canaan, Connecticut [1950] in: WHITNEY, David, KIPNIS, Jeffrey. Philip Johnson: the Glass House. New York: Pantheon Books, 1993, p. 8-15.

JUDD, Donald. Objetos Específicos [1965]. In: FERREIRA, G; COTRIM, C. (Org.). Escritos de Artistas - anos 1960/1970. Rio de Janeiro: Jorge Zahar; Funarte, 2006, p.96-106.

MORRIS, Robert. O tempo presente do espaço [1978]. In: FERREIRA, G; COTRIM, C. (Org.). Escritos de Artistas - anos 1960/1970. Rio de Janeiro: Jorge Zahar; Funarte, p.96-106, 2006

KRAUSS, Rosalind. A escultura no campo ampliado [1979]. Gávea: Revista semestral do Curso de Especialização em História da Arte e da Arquitetura no Brasil, Rio de Janeiro, n.1, p.8793, 1984.

KWON, Miwon. Um lugar após o outro: anotações sobre site- specificity. Revista Arte e Ensaios. Rio de Janeiro, ano XV, n.17, p.167-187, dez. 2008.

Web

ALVES, Margarida Brito. As escolhas dos críticos: Donald Judd por Margarida Brito Alves: Museu Coleção Berardo/ Vídeos, 2017. Disponível em <https://www.youtube.com/ watch?v=tE7kRY2cbJA>. Acesso em 10/12/2017.

CONVERSATIONS in Context: Paul Goldberger. Disponível em <http://theglasshouse.org/media/ conversations-in-context-paul-goldberger/>. Acesso em 18/12/2017.

JOHNSON, Philip. Walking tour with Philip Johnson. Entrevista concedida a Eleanor Devens, Franz Schultz, Jeffrey Shaw, Frank Sanchis. 1991. Disponível em <http://theglasshouse. org/explore/the-glass-house/>. Acesso em 10/12/2017.

LAWRENCE, James. Donald's Judd Works in concrete. In: Chinati Foundation newsletter. 2010. vol. 15. Disponível em <https://chinati.org/pdf/newsletter15.pdf>. Acesso em 22/12/2017. Disponível em <http://theglasshouse.org/learn/donald-judd/>. Acesso em 10/12/2017. 